\title{
Diagnóstico em psicanálise: da estrutura ao discurso*1
}

\section{Diagnosis in psychoanalysis: from structure to discourse}

Isa Gontijo Moreira*2 Antônio M. R. Teixeira*3

\begin{abstract}
O presente artigo propõe uma investigação acerca da questão do diagnóstico diferencial no contexto da prática de orientação psicanalítica. Trata-se de uma pesquisa traçada diante de uma constatação clínica que se refere à operacionalidade do diagnóstico estrutural, um apontamento de uma perspectiva na qual a orientação do manejo clínico perpassa não pelo rigor classificatório preestabelecido, mas factualmente pela questão do sujeito em sua relação com o Outro, sua posição de discurso.
\end{abstract}

Palavras-chave: Diagnóstico, psicanálise, estrutura, posição de discurso

*1 Artigo baseado na dissertação acadêmica financiada pelo Conselho Nacional de Desenvolvimento Científico e Tecnológico - CNPq, intitulada Diagnóstico em psicanálise: da estrutura ao discurso, Programa de Pós-Graduação em Psicologia, Faculdade de Filosofia e Ciências Humanas, Universidade Federal de Minas Gerais - UFMG, Belo Horizonte, MG.

*2, ${ }^{3}$ Universidade Federal de Minas Gerais - UFMG (Belo Horizonte, MG. Brasil). 
A questão nosológica tem se apresentado como um problema nas pesquisas em psicanálise a partir de casos limítrofes em que o diagnóstico se apresenta como um enigma. Não são raras as pesquisas que se propõem a discutir os casos a partir de nomeações como limítrofes, transestruturais, borderline, entre outras. O termo psicose ordinária surgiu justamente de uma pesquisa nesse sentido, na qual Jacques-Alain Miller, partindo desse contexto, propôs práticas clínicas de conversação que, pautadas por discussões sobre casos inclassificáveis, tinham como objetivo pensar outro tipo de orientação teórica para o diagnóstico.

Não foi, entretanto, esse o caminho por onde passou esta pesquisa. Não se buscou questionar qual diagnóstico seria possível para os casos que aqui serão apresentados, o problema surgiu diante do diagnóstico claro e clássico como insuficiente para aquilo que orienta a condução clínica desses casos. A questão da insuficiência constitutiva do diagnóstico foi, de modo mais específico, o ponto de convergência prioritário em torno do qual a pesquisa foi situada, tendo em vista o objetivo de localizar o que era determinante, em cada caso, na tentativa de extrair daí uma metodologia diagnóstica.

O que se apresenta a partir dos casos a seguir é o modo como um diagnóstico, no momento da condução clínica, torna-se insuficiente uma vez que não é capaz de munir, por si só, o psicanalista de elementos orientadores. Foi preciso, então, situar a operacionalidade advinda da emergência da noção de diagnóstico como orientação para a prática da psicanálise. $\mathrm{O}$ que se almeja, pela abordagem de casos com diagnósticos clássicos, é demonstrar como essa categoria pode não ser o fator orientador pilar da prática clínica, já que, a partir de um mesmo diagnóstico foram construídos manejos clínicos completamente díspares.

Entende-se que há, logo de saída, uma espécie de paradoxo posto à teoria psicanalítica na medida em que ela não responde à categorização normativa dos transtornos mentais, já que a própria noção de 


\section{ARTIGOS}

categoria subverte seu axioma da unicidade do caso clínico. Procura-se, então, identificar qual nosologia seria possível para a psicanálise em termos de acolhimento do sujeito ao nível do discurso, uma nosologia que abarcasse uma metodologia clínica capaz de cotejar a singularidade do caso clínico com preceitos diagnósticos universais.

Este trabalho começa, portanto, com o material clínico, uma vez que esta é uma questão essencialmente clínica. Parte-se da análise de duas vinhetas de casos acompanhados pelo projeto de extensão "A construção do caso clínico", do Ambulatório Bias Fortes da Universidade Federal de Minas Gerais (UFMG), em que o estabelecimento do diagnóstico não operou como direção de tratamento na contingência prática. Trata-se de dois casos diagnosticados como esquizofrenia paranoide (F.20), acompanhados em longo prazo pelo projeto e que são aqui retomados a partir de trabalhos anteriores.

\section{Marcelo $^{1}$}

Marcelo foi encaminhado ao Ambulatório Bias Fortes para acompanhamento psiquiátrico no ano de 2008, quando apresentava fenômenos de alucinação verbal, sentimentos persecutórios, medo de sair às ruas, sensações de conspirações e pânico de policiais. Nasceu em uma família de sete irmãos e viveu com sua mãe até antes de se casar. Hoje, com 53 anos, é divorciado separou-se de sua esposa depois de oito anos de união, por uma decisão dela que ele diz não compreender. Tem uma filha de 23 anos, fruto desse relacionamento, filha que, atualmente, mora com ele em um apartamento alugado.

Antes do desencadeamento, Marcelo já apresentava alguns fenômenos de caráter psicótico, embora discretos. Relatou que seus problemas começaram quando trabalhava como contador em uma empresa e passou a não conseguir mais se concentrar, perdia a atenção, não era mais capaz de fazer cálculos. Nessa época, no ano de 2004, já separado, passou a receber investidas sexuais da namorada de um colega de trabalho. Depois disso Marcelo declarou ouvir dela a seguinte ameaça: ela contaria a seu namorado sobre o envolvimento. Ele decidiu, então, falar ele mesmo sobre a situação com o colega, que, por sua vez, respondeu que não se importava, que os dois podiam "ficar" (sic).

${ }^{1}$ Nome fictício. Caso retomado a partir da dissertação de mestrado de Ana Paula Santos (2010), intitulada A clínica da frase: considerações sobre o invariante do sintoma na psicose. 
Quando Marcelo ficou com a garota, foi avisado de que o colega queria vê-lo. Sentindo-se perseguido, teve muito medo e passou a se esconder em casa sem de lá sair para nada, até que o colega o procurou para dizer que tal história de perseguição era infundada e que, na verdade, tinha por ele simpatia. Além disso, Marcelo trouxe relatos de muitas agressões verbais em seu núcleo familiar, principalmente por parte de uma irmã. À época, relatou que, mesmo se afastando dela para não ouvir as agressões, "as vozes continuam entrando no ouvido e repetindo na cabeça" (sic).

O franco surto psicótico foi desencadeado após uma viagem para ver a ex-esposa e a filha, que até então moravam em outra cidade. No trajeto, duas garotas acusaram Marcelo de dirigir-se a elas por meio de gestos obscenos, fato que resultou em abordagem policial. Marcelo acabou sendo levado para a delegacia da cidade, onde ficou retido por horas em uma cela sob a acusação de abuso e de assédio. O paciente marcou o fato como um episódio de extrema "humilhação" e "injustiça" (sic).

O diagnóstico de Marcelo se pautou, então, em fenômenos elementares clássicos revelados no momento de seu desencadeamento: automatismo mental, dissociação da realidade factual, alucinações auditivas e fenômenos 742 ligados à imposição do pensamento. A partir da sintomatologia apresentada, o caso foi diagnosticado como uma esquizofrenia paranoide (F.20), e, para o paciente, foi recomendado o uso de psicofármacos antidrepressivos e antipsicóticos. O elemento da inocência paranoica, segundo a fórmula que Lacan ditou em 1965, foi destacado como fundamental para o diagnóstico estrutural.

No decorrer do tratamento, foi preciso, todavia, identificar de que forma a posição discursiva do sujeito apontava para uma estabilização dos sintomas. Marcelo passava meses, por vezes anos, numa queixa incessante sobre maus-tratos de seus familiares, explorações em situações de trabalho e abusos financeiros advindos primeiramente da mãe, depois da esposa e então da filha. Durante esses períodos de queixa, não manifestava nenhum tipo de confusão psíquica ou sintomatologia psicótica. Entretanto, bastava que recebesse uma ligação do banco ou da imobiliária acusando-o de algum débito pendente para que Marcelo se mostrasse desorganizado.

Segundo Santos (2010), o que estava em jogo nesse caso era o apoio de Marcelo em identificações nas quais invariavelmente ele precisava ocupar uma posição de ser o objeto, $(x)$, que sofre injustiça de um Outro, (y). São muitos os episódios em que é possível reconhecer essa construção como um elemento invariante. Marcelo vendeu a casa construída para a família por um valor muito abaixo do real, fato que o deixava com uma sensação de ter sido injustiçado, 


\section{ARTIGOS}

embora a oferta tenha partido do próprio sujeito. Foi trabalhar com a tia e descobriu estar sendo roubado por ela. A tia o expulsou de casa cometendo contra ele uma "grande injustiça" (sic.). Quando decidiu morar com o irmão, este o levou para morar com a mãe, enganando Marcelo, que se viu sem alternativas diante desse fato. Invariavelmente, ele foi vítima de uma grande injustiça.

Dessa forma, injustiçado, significante presente no episódio de desencadeamento da psicose como tal e nos abusos que sofria cotidianamente da filha, é o que representa Marcelo em seu sintoma; é a localização de gozo que permite certo apaziguamento e, sobretudo, sustenta esse sujeito em suas relações sem que haja uma desestabilização do ponto de vista clínico. Santos (2010) formalizou a aparente ordenação do mundo para Marcelo, baseada no significante da injustiça, da seguinte forma:

\begin{tabular}{|c|c|c|}
\hline Ser o (x) & que é injustiçado por & (y) \\
\hline Empregado & & Patrões \\
\hline Marido & & Esposa \\
\hline Sobrinho & & Tia \\
\hline Filho/Irmão & & Mãe/Irmãos \\
\hline
\end{tabular}

Tal operação permitiu, a partir do sistema de ordenação significante construída pelo próprio sujeito, identificar uma posição de gozo que aponta certa estabilização ao modo do sujeito, circunscrevendo o invariante do sintoma na construção desse caso clínico.

\section{Valéria $^{2}$}

Valéria, 44 anos, iniciou seu acompanhamento no Ambulatório Bias Fortes no ano de 1999, a partir do encaminhamento da equipe de psicologia do Hospital das Clínicas da UFMG. Durante a anamnese, Valéria queixava-se das alucinações auditivas de conteúdo persecutório, relatando que se sentia observada e que percebia ser o alvo da conspiração de outros. Segundo a paciente, esses sintomas tiveram início em decorrência de uma situação de

${ }^{2}$ Nome fictício. Caso apresentado na dissertação de mestrado A demissão do Outro na esquizofrenia: o dito esquizofrênico sem a ajuda de nenhum discurso estabelecido (2016), de autoria de Ana Luiza Mota Santanna. 
estresse no trabalho, em 1995. Relatou que, ao trabalhar como operadora de caixa, havia sido acusada de roubo pelo chefe, situação que chegou a envolver a emissão de um boletim policial. A paciente relatou, ainda, que trabalhava muito e não descansava, sobrecarregando-se com horas extras, até que começou a errar, a atrasar as tarefas e a chorar no trabalho. Foi nessa ocasião, a pedido do seu patrão, que procurou ajuda médica, sendo, então, encaminhada para um hospital psiquiátrico onde ficou internada por um breve período.

$\mathrm{Na}$ ocasião da anamnese, queixava-se também de não conseguir ficar "em lugares cheios e apertados", de estar ouvindo vozes e de se sentir observada, alegando que todas as pessoas falavam dela. Dizia estar "se sentindo estranha", como se suas roupas não fossem suas. Sentia-se perseguida em sua vizinhança, que ela julgava hostil e invejosa. Declarava estar mais agressiva e irritada. Referiu-se, ainda, a um enorme incômodo decorrente do ganho de peso de $25 \mathrm{~kg}$ advindo de um tratamento anterior.

Valéria relatou ter tido uma infância simples e tranquila, entremeada de desentendimentos com os colegas da escola que faziam com que ela chorasse constantemente; por isso, procurava evitar contatos. Finalizou o ensino médio profissionalizando-se em segurança do trabalho, e iniciou sua vida laboral em 1988 como operadora de caixa. Permaneceu nessa função até o desencadeamento de seus sintomas e sua posterior demissão em 1999. Após a demissão, tinha o interesse de buscar outra atividade para exercer: pensou em estudar para um concurso dos Correios, matriculou-se em um curso pré-vestibular visando prestar vestibular para administração de empresas. Entretanto, seus planos não foram postos em prática. Relatou que não conseguia passar na fase das entrevistas quando buscava emprego. Por fim, tentou recomeçar a trabalhar como vendedora na loja de uma amiga, mas o cargo durou apenas cerca de um mês, pois “a loja foi à falência” (sic). A partir daí, mostrou-se desanimada e incapaz de fazer qualquer coisa, permanecendo inativa e tendo como única renda o "auxílio-doença” (sic).

Atualmente, a paciente reside com a mãe e com a irmã, sendo suas relações interpessoais basicamente exclusivas à família. Valéria relata não ter muitos amigos, não menciona envolvimentos amorosos. Justifica-se dizendo que tem uma desconfiança com os outros, além de sentir muita dificuldade em frequentar lugares movimentados e barulhentos. Passa a maioria de seus dias em casa, no sofá, sendo que, esporadicamente e por tempo limitado, busca praticar alguma atividade física.

Aqui também o diagnóstico, a partir da sintomatologia, foi o de esquizofrenia paranoide (F.20), sob o traço da mesma estrutura da inocência paranoica (Soler, 2007) e pautado nos fenômenos elementares descritos. O 


\section{ARTIGOS}

caso de Valéria, contudo, indicou como ponto central no funcionamento do sujeito, uma queda da intencionalidade, uma volatização da intenção que não lhe permite se lançar no laço discursivo em busca de seu desejo.

Ela iniciou, por diversas vezes, a prática de atividades físicas a fim de perder peso, práticas que eram precocemente interrompidas. O mesmo acontecia quando se propunha a estudar ou a buscar um emprego. Refratária a qualquer possibilidade de laço social, apresentou notória inquietação e desestabilização em períodos como as festas natalinas, aniversários, casamentos ou velórios que reuniam a família. Por vezes, a paciente queixou-se de um vazio que a acometia, condenando-a à inércia, ainda que houvesse um investimento aplicado a determinada circunstância. Esse vazio foi por ela nomeado como uma "agitação" (sic) sobre a qual não conseguia falar. Quando anunciou o desejo de colocar fim à própria vida, esse vazio apareceu ainda, em sua fala, marcado pelo significante "sem sentido" (sic).

Segundo Santanna (2016), essa inércia mortificante, que impossibilita Valéria de se ancorar minimamente no campo do Outro, surge como uma insígnia de um gozo não domesticado pela ação discursiva, de forma que ela permanece imersa em um constante e ininterrupto sentimento de estranheza em relação às condutas codificadas socialmente. Os discursos, como condutas codificadas, têm em comum o fato de sempre sustentarem uma virtualidade intrínseca nas relações, um ponto de ancoragem para o desejo. A vontade fugaz de Valéria nada mais é que um efeito lógico do colapso de um sistema que, para ela, não é representativo. Ciente da inconsistência do Outro, resta a ela passar os dias sentada no sofá.

A marca da queda da intencionalidade ou a dificuldade de engajamento em qualquer laço social aparecia todas as vezes em que ela se propunha alguma atividade que passava por um laço com o outro: aulas de ginástica, cursos profissionalizantes, busca de emprego. Esse certo exílio do laço social era a posição que Valéria costumava ocupar, sendo, assim, seu elemento sintomático e estabilizador.

\section{O problema}

A apresentação dos casos evidenciou a possibilidade de encontrar, em uma mesma estrutura, conduções clínicas muito distintas. É uma pesquisa que não se justifica, portanto, pela clara insuficiência de um manual psiquiátrico de validade contestável como o DSM: aqui o diagnóstico estrutural ou fenomenológico da psicanálise mostrou-se também insuficiente. São casos cujo 
encaminhamento mostra a divergência na categorização nosológica: apesar de estarem incluídos em tais categorias de forma representativa, a solução encontrada foi retirada da singularidade de cada caso. Em que pese o perfeito encaixe de ambos os casos nos critérios diagnósticos preestabelecidos pela estrutura ou pelo fenômeno, a orientação do manejo clínico mostra a divergência que perpassa não pelo rigor classificatório. Passaria, então, por onde?

\section{Da estrutura... ao discurso}

Freud, em "Sobre o início do tratamento" (1913/1996c), recomenda aos analistas que façam um "experimento preliminar" no princípio de uma análise, por uma ou duas semanas, para que se empreenda uma sondagem do caso e para que se estabeleça o diagnóstico diferencial (p. 140). O autor declara que é de extrema utilidade que o analista assim proceda, como forma de evitar erros práticos que desacreditem seu método de tratamento.

No que tange aos critérios diagnósticos estabelecidos por Freud, o que se extrai de seus relatos clínicos é que havia uma atenção direcionada aos sintomas típicos (paralisias histéricas, rituais obsessivos...), mas, sobretudo, uma análise convocada pelo modo como cada sujeito se posicionava diante de seu sintoma. É o que fica explícito, a título de exemplo, no caso de Elisabeth (Freud \& Breuer, 1895/1996b, Caso 5): essa paciente, no lugar de demonstrar sofrimento diante da enfermidade que acometia seus músculos das pernas, demonstrava a mais plena indiferença, a sua belle indifférence, o que imediatamente convocou a atenção de Freud e lhe permitiu dali extrair a fala da paciente. O psicanalista estabeleceu, assim, como função capital para o diagnóstico, a distinção de casos que poderiam ser submetidos ao processo analítico de forma a trazer benefícios aos analisantes e casos de pacientes cujo quadro clínico não apresentariam critérios para estarem, por exemplo, em condições de atuar sob associação livre.

Na visão de Freud, a energética seria responsável por essa amarração entre o inconsciente, as pulsões, como componentes da vida psíquica, e elementos constituintes últimos da matéria, dentro de um quadro físico-químico que esquematizaria sua identidade epistêmica, seu modo de construção (Aussoun, 1981/1983).

Lacan, por sua vez, não pôde mais dispor do fisicalismo de Freud. Ele se vale, então, para tratar do problema do estruturalismo. Lacan propõe substituir a energética freudiana por essa nova metáfora especialmente porque a estrutura 


\section{ARTIGOS}

não assume a forma de uma cadeia de sentido, mas de um espectro dotado de certas propriedades que se conjugam. A estrutura não seria, então, uma representação, mas uma escrita que não se presta à imaginação (Alvarenga, 2007).

Miller (2001) conduz a questão partindo da ideia de que a inclusão da estrutura no real é o que possibilitaria à psicanálise ultrapassar o pluralismo das teorias privadas. Essas teorias privadas decorrem da perspectiva nominalista declaradamente rechaçada por Lacan, que foi claro ao se posicionar contra a crença no nominalismo dos casos um a um em detrimento do realismo das estruturas.

É fato que a estrutura na psicanálise lacaniana tornou-se um operador conceitual capaz de definir os limites e as principais balizas a partir das quais teoria e clínica poderiam ser pensadas com maior precisão. Ao passo que Freud, através de seu ponto de vista econômico-tópico, buscava distinguir as classes sistemáticas de adoecimento psíquico conforme os meios empregados pelo sujeito para se defender de exigências pulsionais, a noção de estrutura inaugura uma modalidade de pensamento que rompe com a busca de uma etiologia da doença pela hermenêutica. Freud segue a linha de sucessão da clínica médica de causalidade orgânica buscando um agente causador da patologia que, se outrora estava ancorado no orgânico, estaria agora, na visão de Freud, no traumatismo sexual. A perspectiva estrutural abre, por sua vez, a presunção de uma causalidade que é intrínseca ao objeto na sua condição de pertencente a um sistema/a uma estrutura, instaurando uma noção de neutralidade no tratamento da patologia psíquica. A noção de estrutura inaugurou, em psicanálise, uma tipologia diagnóstica baseada no sintoma que permitiu ao analista apreender a manifestação psicopatológica com uma precisão tal qual a de um cientista, afastando-o de uma abordagem estritamente intuitiva.

Fato é que, apesar de ser clara a pontualidade com a qual o termo estrutura aparece no texto freudiano, seu discurso permite a interpretação de um raciocínio pela leitura estrutural, que é feita por Lacan (Sadala \& Martinho, 2012). Lacan propôs para pensar no âmbito da psicanálise a trajetória de assimilação das noções de diagnóstico presentes na tradição psiquiátrica clássica, uma classificação nosológica essencialmente baseada no modelo estrutural. Mas por que ao adotar formas de se estabelecer diagnósticos, Lacan apostava na estrutura?

A questão começa no fato de que há, para Lacan (1953/2003a), algo de constitutivo que concerne ao ser falante, uma vez que a todos é dada a preexistência de uma ordem simbólica - o Outro - ordem que se coloca para o sujeito infantil e diante da qual será preciso que ele responda. Tem-se 
que o que é dado na estrutura, como estrutura de linguagem, é uma incompletude intrínseca, marca da passagem do ser que age regulado pelo instinto ao ser falante, regulado pelo desejo. Há algo do sexual, do ser habitado pela linguagem, que se opõe à etiologia utilitária do órgão; portanto, transpõe-se a ordem da necessidade e da reprodução. No âmbito do ser falante, não há uma programação, como há naquela dada pelo instinto, sobre o sexo. $\mathrm{O}$ que há é uma perda inaugural que não pode ser transposta pelo Outro, que também aloja esse vazio de sentido. Diante dessa hiância aberta no registro da linguagem como um furo nas significações, é dado um movimento - de significantes - para o Outro preencher, e é nesse fluxo significante que o sujeito vem a emergir. Essa falta na estrutura da linguagem se apresenta então de modo operativo, já que, se nada fala, se a estrutura está plena, completa, não há espaço para uma movimentação. O elemento ausente, como um buraco na cadeia simbólica, é então operativo, para que, pela via do buraco, possa surgir um sujeito desejante:

O desejo é aquilo que se manifesta no intervalo cavado pela demanda aquém dela mesma, na medida em que o sujeito, articulando a cadeia significante, traz à luz a falta-a-ser com o apelo de receber seu complemento do Outro, se o Outro, lugar da falta, é também o lugar dessa falta. (Lacan, 1958/1998a, p. 633)

O que há, portanto, de emblemático no movimento que se apresenta na histeria como tal e no sonho da "Bela Açougueira" (1958/1998a) é o que esse saber quer dizer no inconsciente sobre o desejo como metonímia da falta-a-ser:

Se o desejo é expresso como insatisfeito, ele o é pelo significante "caviar", na medida em que esse significante o simboliza como inacessível; mas a partir do momento em que ele desliza como desejo no caviar, o desejo de caviar é sua metonímia, tornada necessária pela falta-a-ser a que ele se atém. (p. 628)

Esse é, portanto, o movimento que Lacan descreve ao abordar as formações do inconsciente, em que um significante tem que se vincular sempre a outro significante, dada sua falta-a-ser, e os sujeitos, assim como seus modos de adoecimento, surgem como efeito dessa vinculação.

Existem, todavia, para Lacan, três modos distintos de lidar com esse furo na linguagem. As noções de estruturas — neurótica, psicótica, perversa —, fundamentos do que chamamos de tipos diagnósticos estruturais, são posições subjetivas quanto a essa ordem simbólica e se diferem pelas marcas de gozo que se dão nesse movimento de engendramento da linguagem.

Em Freud, já no texto "As neuropsicoses de defesa" (1894/1996a), há uma distinção fundamental entre as diferentes formas — que ele denomina 


\section{ARTIGOS}

como defesas - com as quais o sujeito joga para lidar com a iminência da castração determinante no complexo de Édipo. Ocorre que, segundo Miller (1998), toda a teorização psicanalítica freudiana tem como ponto de partida um objeto inexistente: o pênis da mãe. Freud parte da teoria sexual infantil pautada na hipótese que as crianças criam de que todos os seres originalmente têm um pênis - não só os humanos, mas principalmente os humanos, e especialmente suas mães. Quando a criança se detém na imagem da mãe ou de uma pessoa do sexo feminino, percebe a ausência do pênis e, então, é tomada pelo horror. Os termos Verdrängung (recalque), Verwerfung (rejeição, forclusão) e Verleugnung (desmentido, renegação) marcam operações fundamentais que o sujeito adota diante da constatação da diferença anatômica entre os sexos e desse horror diante da negativa do órgão que a vagina representa. E é também sob essas saídas que se erguem formações de identidade para os sujeitos: no caso da menina, ela se põe do lado da falta e se vê como castrada, tomando o pênis do pai como objeto de desejo; o menino, por sua vez, desenvolve o temor da castração por seu pai (porque, se a menina ou a mãe foi castrada, ele também pode ser), que lhe imputa a condição de renunciar ao desejo pela sua mãe.

Para Lacan (1958/1998c), o complexo de castração inconsciente tem uma função de nó, que primeiramente está posto a fim de estruturar a dinâmica dos sintomas neuróticos, perversos e psicóticos, "numa regulação do desenvolvimento que dá a esse primeiro papel sua ratio, ou seja, a instalação, no sujeito, de uma posição inconsciente sem a qual ele não poderia identificar-se com o tipo ideal de seu sexo" (p. 692). Se, para Freud, o Édipo é um drama entre o pai, a mãe e a criança; para Lacan, o Édipo é uma armação significante mínima: a metáfora paterna, tal qual o enredo edipiano, constitui o fundamento estrutural do sujeito.

Em O seminário. Livro 3. As psicoses, em que a questão da estrutura faz-se presente e marcadores diagnósticos são discutidos em mais de uma lição, Lacan (1955-1956/2010, p. 21) define Bejahung (afirmação primordial) como uma admissão da Lei do Pai, sem deixar de indicar, contudo, que essa lei nem sempre se faz presente, pois pode ser que o sujeito recuse o acesso, no seu mundo simbólico, de algo que nada mais é que a castração. Assim, a Verwerfung, forclusão da lei, opõe-se à Bejahung, que é sua afirmação. Formam, ambas, mecanismos de um par dicotômico, como afirma Lacan (1955-1956/2010, p. 100).

Diante do que aqui chamamos Bejahung, ou seja, diante da afirmação primordial de uma ausência no nível da cadeia significante, existem duas 
possibilidades primordiais postas para o sujeito: Bejahung seguida de Recalque (Verdrängung), que é o que verificamos nos sintomas neuróticos, e Bejahung seguida de Recusa (Verleugnung), fenômeno fetichista da perversão. Acontece que, se não há Bejahung, resta algo a ser simbolizado que, para Lacan (1955-1956/2010), manifesta-se no real: "tudo que é recusado na ordem simbólica, no sentido da Verwerfung, reaparece no real" (p. 22). Eis o maquinismo da alucinação, dos sintomas psicóticos. Portanto, diante da impossibilidade de uma substituição do objeto perdido na linguagem, no plano metafórico dos significantes, esse objeto é tomado em sua representação real. Trata-se da forclusão (Verwerfung) da falta na cadeia significante, falta que faz a cadeia deslizar.

As estruturas clínicas baseiam-se, então, em operações fundamentais de formação do sintoma que Lacan localiza no texto de Freud: recalque (Verdrängung), recusa (Verleugnung) e forclusão (Verwerfung). Dessas três operações estruturantes decorrem três tipos clínicos, respectivamente: neurose, perversão e psicose. O recalque (Verdrängung), operação estruturante da neurose, talvez tenha sido o único mecanismo reconhecido por Freud indubitavelmente. Quanto à recusa (Verleugnung), própria à perversão, e quanto à 750 forclusão (Verwerfung), própria à psicose, Freud mantinha-se ambíguo, tendo sido Lacan o responsável por identificar no texto freudiano tais operações como estruturais.

Verdrängung, no texto freudiano, designa um processo de clivagem, uma separação entre representação e afeto nomeada como recalcamento (Freud, 1925/1996). De acordo com Hanns (1996), o recalque é um movimento de afastamento, de desalojamento de um incômodo do plano simbólico. Ainda na descrição do autor, "conotativamente, verdrängen remete a uma sensação de 'sufoco', 'incômodo', que leva o sujeito a desalojar o material que o incomoda. Contudo, apesar de ter sido afastado, tal material permanece junto ao sujeito, pressionando pelo retorno e exigindo a mobilização de esforço para mantê-lo longe" (Hanns, 1996, p. 355). Desalojar o incômodo implica, entretanto, que primeiramente ele tenha sido reconhecido, ou seja, simbolizado, afirmado (Bejahung). O não querer saber da castração do neurótico pressupõe que já se saiba dela, que tal realidade tenha feito sua inscrição. Propriamente dizendo, o recalcamento se dá como um "não querer saber sobre isso", que faz do neurótico um alienado em relação a seu saber inconsciente. Tendo havido, então, um significante originalmente expulso na neurose, sua reatualização é representada como um furo na cadeia significante; esse furo, como já apontado anteriormente, é o que permite o espaço vazio na estrutura, que, por sua vez, 


\section{ARTIGOS}

possibilita a sucessão dos significantes de onde advém o sujeito. No texto de Freud, essa perda é a perda do objeto como coisa — das Ding -, condiciona as relações do sujeito - que, daí por diante, serão parciais, apenas com seus traços - e apresenta o neurótico a uma inesgotável nostalgia sintomática. Segundo Lacan (1955-1956/2010), o recalque, para o neurótico,

[...] é uma língua, uma outra língua que ele fabrica com seus sintomas, isto é, se é um histérico ou um obsessivo, com a dialética imaginária dele e do outro.

O sintoma neurótico desempenha o papel da língua que permite exprimir o recalque. É justamente aquilo que nos faz ver claramente que o recalque e o retorno do recalcado são uma só e a mesma coisa, o direito e o avesso de um só e mesmo processo. (p. 77)

Assim, na histeria, a compensação da falha no recalque se dá pela exacerbação da falta. O sujeito histérico é vítima do Outro, incompleto, que lhe condenou à insatisfação. Resta, então, a estratégia de apontar todo sofrimento causado pelo Outro indicando seus furos, ao mesmo tempo que esse sujeito, o histérico, não permite que os seus próprios furos se tornem evidentes. A obsessão, estratégia oposta à da histeria, representa a compensação da falha no recalque pela obturação da falta. O obsessivo faz de toda a sua vida uma maneira de sanar as faltas do Outro, os defeitos do mundo.

$\mathrm{Na}$ Verleugnung, recusa perversa, a Bejahung segue um outro pressuposto. A Verleugnung marca uma posição ambígua quanto à admissão, no plano simbólico, do significante da castração. Para Hanns (1996), Verleugnung tem um sentido linguístico de ser uma "negação que permanece entre a verdade e a mentira", tal como no exemplo em que o sujeito nega a própria presença: "mandar dizer que não está presente" (p. 303). Nos dizeres do autor, "o termo quase sempre se refere a uma tentativa de negar algo afirmado ou admitido antes" (p. 303). O fetiche, representante da castração por uma Verleugnung, funciona, então, como um desmentido que implica especificamente uma relação com a questão da verdade da castração, na medida em que se trata de des-admitir a castração materna, sendo um instrumento que ao mesmo tempo a acata e a nega. No texto "Fetichismo" (1927/1996d), Freud fala da cisão entre a realidade e aquele ponto que o sujeito recusa: o pênis da mãe. Convivem, lado a lado, a rejeição e a afirmação da diferença sexual representada na castração materna:

O fetiche é um substituto para o pênis [...], um pênis específico e muito especial, que foi extremamente importante na primeira infância, mas posteriormente perdido. Isso equivale a dizer que ele normalmente deveria ter sido abandonado; o fetiche, porém, se destina exatamente a preservá-lo da extinção. (p. 155) 
Como já apontado, oposta às duas demonstrações de Behajung, está, então, a Verwerfung, o que, segundo Lacan (1955-1956/2010), "aponta para uma sorte completamente diferente" (p. 21). A noção de Verwerfung, linguisticamente falando, advém do termo jurídico preclusão, com a conotação de descarte, de eliminação (Hanns, 1996). Traduzida dos textos de Freud como rejeição e por Lacan (1954-1955/1985) como forclusão, Verwerfung vem falar da impossibilidade originária de inscrição do elemento significante da lei ab origine, lei que representa uma contenção de gozo $(\mathrm{P})$ na cadeia significante, no grande Outro, conforme já apresentado neste trabalho. Segundo França (2006), sobre o campo da psicose, pode-se dizer que a defesa diante da castração mostra-se de tal modo decidida que a castração chegaria a ser completamente eliminada do espaço simbólico, colocando o sujeito diante de uma pura afirmação infinita, império do gozo. Na psicose, como o furo na cadeia significante não está colocado, a possibilidade de emergência do sujeito só pode se dar na luta para conseguir estabelecer uma finitude nessa afirmação desmesurada. Tal tarefa é demonstrada, por exemplo, quando o psicótico, ao corporificar esse gozo sem borda em um objeto externo (em uma pessoa por muitas vezes), consegue cerceá-lo dentro de seus limites espaciais e torná-lo menos invasivo (França, 2006). Entretanto, se, para Lacan (1955-1956/2010), tal operação se mostra de uma sorte completamente diferente daquela encontrada no recalque, é porque ela se mostra vulnerável a qualquer paradoxo que coloque em evidência o necessário ponto de dialetização que o falo, significante da castração, possibilita. O que na neurose vem na forma de representações na cadeia significante, de metáforas, na psicose vem na literalização - modo como o real aí se apresenta. Essa literalização ocorre, por exemplo, nas alucinações:

Há uma relação estreita entre, de um lado, a denegação e o reaparecimento na ordem puramente intelectual do que não está integrado pelo sujeito, e, de outro, a Verwerfung e a alucinação, isto é, o reaparecimento no real do que é recusado pelo sujeito. (Lacan, 1955-1956/2010, p. 23)

É possível distinguir, então, tipos diagnósticos estruturais — o neurótico, o perverso e o psicótico - porque há algo de subjacente a esses sujeitos que os agrupa mesmo que contraditoriamente: a estrutura da linguagem. O que joga como uma identificação entre o grupo dos neuróticos, o grupo dos psicóticos e o grupo dos perversos é o subjacente da estrutura.

Todavia, há dificuldades postas ao modelo estrutural aplicado à psicanálise. A ressalva está relacionada a uma ocorrência bastante específica que faz de Lacan um estruturalista singular no século XX. Enquanto os estruturalistas elidem o sujeito da estrutura, tornando-o uma categoria supérflua, Lacan, por 


\section{ARTIGOS}

sua vez, serve-se do sujeito justamente para formalizar todo seu constructo teórico. Ele denuncia, em "A ciência e a verdade", de 1965, a insuficiência do estruturalismo alegando que essa corrente teórica desconsidera a natureza do mitante em sua análise das mitologias, sendo rejeitado para fora do campo da estrutura o relativo a seu assentimento - "O saber, portanto, é ali bem separado do sujeito" (Lacan, 1965/2003b, p. 876). Para Lacan, a responsabilidade da decisão é colocada como própria à condição de sujeito, independente do determinismo da estrutura simbólica que para o sujeito se impõe. Esse é o ponto em que Lacan (1965/2003b) se diferencia do determinismo da estrutura, considerada, por ele, uma "redução que negligencia o sujeito" (p. 879)

Em virtude da estrutura lacaniana do sujeito e, em particular, de sua disposição para interrogar o sujeito de seu lugar de responsabilidade, mesmo dentro da cadeia simbólica que o antecede, surge em psicanálise uma noção diagnóstica que não se atém aos princípios classificatórios estruturalistas. A expressão diagnóstico de posição no discurso foi-nos apresentada por ocasião da publicação de Carlo Viganó (1999) em suas elaborações sobre a construção do caso clínico. Na sua pesquisa, o que Viganó buscava apreender dos casos era um ajuizamento da situação imediata em que o sujeito se apresenta em relação ao Outro, no caso, o Outro institucional ou a própria equipe de tratamento.

Para compreender o diagnóstico de discurso, há então de se interrogar, primeiramente, quem é o Outro para o sujeito e como o sujeito interage com esse Outro, tendo em vista a teoria lacaniana da linguagem: "Há dois outros que se devem distinguir, pelo menos dois - outro com ' $\mathrm{A}$ '3 maiúsculo e um outro com 'a' minúsculo, que é o eu. O Outro, é dele que se trata na função da fala" (Lacan, 1954-1955/1985, p. 297). Lacan distinguiu pequeno e grande Outro para falar da entrada do sujeito no campo simbólico, do assujeitamento à cadeia simbólica que a ele preexiste. $\mathrm{O}$ pequeno outro (a) é o igual, o semelhante humano; o grande Outro (A), a representação do campo simbólico e da linguagem. Logo, o sujeito advém do elo entre discurso do Outro, como sistema simbólico, e da realidade do inconsciente, que se configura numa realidade fantasmática.

A novidade lacaniana é a de pensar o sujeito não como um dado, não como um significado decorrente de um significante qualquer, mas, sobretudo, a partir de um investimento libidinal em uma determinada significação

${ }^{3} \mathrm{O}$ grande Outro como conceito é designado pela letra A na bibliografia psicanalítica pois se mantém a correspondência com a língua francesa de seu autor, Lacan, em que Outro é Autre. 
- resultado de um investimento particular na cadeia dos significantes. A confluência entre o corpo biológico e a linguagem que esse corpo habita é o corte contingente em que o sujeito emerge, é a construção no sistema simbólico como resposta ao real. Essa resposta não obedece nunca, por definição, ao modo preditivo da cientificidade do experimento, pois é um trabalho que remete à elaboração da cadeia metonímica singular de um sujeito. É exemplar o caso de Jean-Jacques Rousseau descrito por Soler (2007): o elemento que promove uma descontinuidade absoluta na vida desse sujeito é a acusação de mexer em um pente. Tal fato poderia passar despercebido na vida de qualquer pessoa, contudo esse elemento contingente estabelece um antes e um depois, marca uma significação determinante na vida do sujeito.

O que aparece, então, na problemática do diagnóstico, é que o modelo classificatório preestabelecido, aos modos cientificistas do experimento, não abarca o modo único de inserção de um sujeito na cadeia discursiva por centrar-se na estrutura da linguagem como unívoca e não no sujeito como uma resposta singular diante do Outro na cadeia dos significantes. Os termos eleitos pela nosografia psicanalítica - neurose, psicose e perversão também são elencados em função do assujeitamento do ser falante à estrutura da linguagem, e seguem o modelo de estrutura como sistema, tal como descrito por Lévi-Strauss.

O que verificamos, portanto, ao avaliar os casos anteriormente apresentados neste trabalho e tantos outros de nossa prática clínica, é que o preenchimento de critérios diagnósticos a partir do cotejamento de fenômenos estruturais orienta certos manejos, mas não se apresenta como centro da problemática clínica, que abarca uma série de especificidades do caso e dos modos de vida do sujeito. Lacan (1973/2003c) já apontava que a nosologia estrutural deveria ser ressituada no âmbito do sujeito, uma vez que não existiria um senso comum do sintoma, e sim a análise do particular:

Com o que indico que o que decorre da mesma estrutura não tem forçosamente o mesmo sentido. É por isso que só existe análise do particular: não é de um sentido único, em absoluto, que provém uma mesma estrutura, sobretudo não quando ela atinge o discurso. (p. 554)

Logo, faz-se necessário estabelecer uma espécie de método para apreensão desse material que escapa ao regime nosológico formal e que, antes de ser um resto, é, ao contrário, o ponto central do tratamento. Trata-se da inserção sempre individual de cada um no discurso, ponto que o determinismo formal da estrutura não permite ver. Há, portanto, através do relato desses casos, uma dimensão do diagnóstico que submete a estrutura ao sujeito, e não o contrário. 


\section{ARTIGOS}

Dizer, portanto, que "o inconsciente é estruturado como linguagem" (Lacan, 1964/1985, p. 25) imputa, no nível do sintoma, uma indeterminação circunstancial que fica à deriva do que tomamos como real na experiência clínica, o impossível de predizer ou controlar que se coloca através do investimento libidinal significante. Se a estrutura da linguagem está para todos, sua apreensão só se dá no nível do particular. E é nesse ponto que Miller (2008) estende a questão da estrutura até o que ele chama de "estruturação espontânea":

Pelo simples fato de que o sujeito fala, pelo simples fato da palavra, o que lhe ocorre, a expressão diz bem, tem relação com o acaso, o imprevisto, com o encontro, como se diz. É o que Lacan sublinha em seu Seminário do Sinthoma: são os acasos que nos fazem ir a torto e a direito. É reconhecer, nos termos de Aristóteles, que a existência se desenrola no reino da contingência. (pp. 56-57)

Isso quer dizer, em outros termos, que pelo simples fato de cada sujeito estar diante do Outro, no discurso - falando e sendo falado - , uma organização se institui a partir de um elemento que não é dado, é construído por cada um e é contingente. A partir desse investimento libidinal em determinados significantes, algo como uma trama toma a forma de uma figura nominativa, que, segundo Miller (2008), é tomada como destino ou vocação.

Captar tal ordem, que vem a emergir a partir de fatos de repetição na vida do sujeito, é o propósito de um diagnóstico orientado pelo discurso, diagnóstico esse que não desconhece que essa articulação de sentido é uma superestrutura, uma vez que se trata de uma estrutura que se sobrepõe a elementos prévios. Para Miller (2008),

Trata-se, portanto, de reconduzir a trama de destino do sujeito da estrutura aos elementos primordiais, fora de articulação, quer dizer, fora do sentido e, porque absolutamente separados, podemos dizê-los absolutos. Trata-se de reconduzir o sujeito aos elementos absolutos de sua existência contingente. (p. 58)

As elaborações dos casos aqui apresentados constituem, dessa forma, tentativas de cotejar, no nível do discurso, as orientações para a condução clínico-psicopatológica de casos de diagnósticos homônimos, Marcelo e Valéria. A modulação das categorias nosológicas no nível do caso a caso introduz por si só uma ordem de singularidade que o tipo clínico não esgota. Por exemplo, apesar de considerarmos o caso de Marcelo uma esquizofrenia, a nominação que propusemos para sua singularidade difere do considerado geral para essa categoria clínica. No entanto, é notório, no ensaio de cada um deles, um movimento que não podia — nem queria - desconsiderar a 
formalização do desenvolvimento nosológico que a clínica estrutural nos coloca, nem deixar de usufruir de referenciais da psicopatologia clínica.

Para Schetjman (2013, p. 316), este é um processo dialético que especifica a impressão ética da psicanálise na psicopatologia: há, por um lado, o caminho que leva do tipo clínico à singularidade subjetiva, mostrando, no nível da contingência, a resistência do caso à tipagem; por outro, há um caminho que retorna sobre o particular e vai ao tipo clínico na leitura da estrutura do sintoma, determinando a não concessão da psicanálise a um nominalismo que rejeita a clínica e a transmissão.

Não poderia ser de outra forma, Freud já advertia desde o início. Em psicanálise, não há como desvendar a abordagem do caso clínico, da transferência e do diagnóstico como tal sem passar pelo ponto singular e circunstancial do sujeito. No um a um. Correlativamente, não é possível se livrar de aspectos psicopatológicos ou estruturais, da formalização clínico-nosológica que afasta a psicanálise de uma abordagem mística ou desavisada do sintoma. Trata-se, para a psicanálise, de sua impossibilidade de falar de um sujeito que não seja o sujeito da ciência.

\section{Referências}

Alvarenga, E. (2007). Variedade dos sintomas, unicidade do tipo clínico. Correio Revista da Escola Brasileira de Psicanálise, 58, 13-22.

Assoun, P.-L. (1983). Introdução à epistemologia freudiana. Rio de Janeiro, RJ: Imago. (Trabalho original publicado em 1981).

França, O. (2006). A Bejahung nas conexões da psicanálise. Psicol. clin. [online], 18(1), 153-163. Recuperado em 22 nov. 2017, de: <http://dx.doi.org/10.1590/ S0103-56652006000100013>.

Freud, S. (1996a). As neuropsicoses de defesa. In Edição Standard Brasileira das Obras Psicológicas Completas de Sigmund Freud (Vol. III, pp. 51-72). Rio de Janeiro, RJ: Imago. (Trabalho original publicado em 1894).

Freud, S. (1996b). A psicoterapia da histeria. In Edição Standard Brasileira das Obras Psicológicas Completas de Sigmund Freud (Vol. II, pp. 271-319). Rio de Janeiro, RJ: Imago. (Trabalho original publicado em 1895).

Freud, S. (1996c). Sobre o início do tratamento (Novas recomendações sobre a técnica da psicanálise I). In Edição Standard Brasileira das Obras Psicológicas Completas de Sigmund Freud (Vol. XII, pp. 139-158). Rio de Janeiro, RJ: Imago. (Trabalho original publicado em 1913). 


\section{ARTIGOS}

Freud, S. (1996d). A negativa. O ego e o id e outros trabalhos. In Edição Standard Brasileira dasObras PsicológicasCompletas de Sigmund Freud (Vol. XIX, pp. 263-269). Rio de Janeiro, RJ: Imago.

Freud, S. (1996e). Fetichismo. In Edição Standard Brasileira das Obras Psicológicas Completas de Sigmund Freud (Vol. XXI, pp. 151-160). Rio de Janeiro, RJ: Imago. (Trabalho original publicado em 1927).

Hanns, L. (1996). Dicionário comentado do alemão de Freud. Rio de Janeiro, RJ: Imago.

Lacan, J. (1984). Conférence chez le Professeur Deniker au Hôpital Sainte-Anne. Bulletin de la Association freudienne, 7, 3-4. (Trabalho original publicado em 1978).

Lacan, J. (1985a). O seminário. Livro 2. O eu na teoria de Freud e na técnica da psicanálise. Rio de Janeiro, RJ: Jorge Zahar. (Trabalho original publicado em 1954-1955).

Lacan, J. (1985b). O inconsciente freudiano e o nosso. In O seminário. Livro 11. Os quatro conceitos fundamentais da psicanálise (pp. 23-32). Rio de Janeiro, RJ: Jorge Zahar. (Trabalho original publicado em 1964).

Lacan, J. (1998a). A direção do tratamento e os princípios do seu poder. In Escritos (pp. 585-652). Rio de Janeiro, RJ: Jorge Zahar. (Trabalho original publicado em 1958).

Lacan, J. (1998b). De uma questão preliminar a todo tratamento possível da psicose. In: Escritos (pp. 537-590). Rio de Janeiro, RJ: Jorge Zahar. (Trabalho original publicado em 1958).

Lacan, J. (1998c). A significação do falo. In Escritos (pp. 692-703). Rio de Janeiro, RJ: Jorge Zahar. (Trabalho original publicado em 1958).

Lacan, J. (2003a). Discurso de Roma. In Outros Escritos (pp. 139-172). Rio de Janeiro, RJ: Jorge Zahar. (Trabalho original publicado em 1953).

Lacan, J. (2003b). A ciência e a verdade. In Escritos (pp. 869-892). Rio de Janeiro, RJ: Jorge Zahar. (Trabalho original publicado em 1965).

Lacan, J. (2003c). Introdução à edição alemã de um primeiro volume dos Escritos. In Outros Escritos (pp. 550-556). Rio de Janeiro, RJ: Jorge Zahar. (Trabalho original publicado em 1973).

Lacan, J. (2010). O seminário. Livro 3. As psicoses. Rio de Janeiro, RJ: Jorge Zahar. (Trabalho original publicado em 1955-1956).

Miller, J.-A. (1998). A criança entre a mulher e a mãe. Opção Lacaniana, 21, 7-12.

Miller, J.-A. (2001). Últimas lições do Cours de Orientation lacanienne, III(4). (Inédito)

Miller, J.-A. (2007). Os casos raros, inclassificáveis, da clínica psicanalítica. São Paulo, SP: Biblioteca Freudiana Brasileira. 
Miller, J.-A. (2008). Orientação lacaniana III, 11 - Coisas de fineza em psicanálise. Rio de Janeiro, RJ: Escola Brasileira de Psicanálise. (Inédito).

Sadala, G., \& Martinho, M. H. (2012). A estrutura em psicanálise: uma enunciação desde Freud. Ágora, XIV(2), 243-258.

Santanna, A. (2016). A demissão do Outro na esquizofrenia: o dito esquizofrênico sem a ajuda de nenhum discurso estabelecido. Dissertação de mestrado. Programa de Pós-Graduação em Psicologia. Universidade Federal de Minas Gerais, Belo Horizonte, MG, Brasil.

Santos, A. (2010). A clínica da frase: considerações sobre o invariante do sintoma na psicose. Revista CliniCAPS, 4(12). Recuperado em 2 nov. 2016, de: <http:// clinicaps.com.br/clinicaps_revista_12_art_04.html $>$.

Schejtman, F. (2013). Sinthome: ensayos de clínica psicoanalítica nodal. Buenos Aires, Argentina: Grama.

Soler, C. (2007). Inocência paranoica e indignidade melancólica. In $O$ inconsciente a céu aberto da psicose (pp. 52-59). Rio de Janeiro, RJ: Jorge Zahar.

Viganó, C. (1999). A construção do caso clínico em saúde mental. Curinga Psicanálise e Saúde Mental, 13, 50-59. Belo Horizonte: EBP-MG.

\section{Resumos}

(Diagnosis in psychoanalysis: from structure to discourse)

This paper proposes an investigation regarding the issue of the differential diagnosis in the context of the psychoanalytic practice. It consists of a research based on a clinical observation that refers to the operability of the structural diagnoses. It points out to a perspective in which the direction of the clinical management is not pervaded by the pre-established classificatory rigor, but by the issue of the subject in his relation with the Other, his discursive position.

Key words: Diagnosis, psychoanalysis, structure, discursive position

(Diagnostic en psychanalyse: de la structure au discours)

Cet article propose une investigation sur la problématique du diagnostic différentiel dans la pratique clinique orientée par la psychanalyse. Il s'agit d'une recherche élaborée à partir de la constatation observée dans la clinique, qui se réfère à l'opérationnalité du diagnostic phénoménologique ou structurel, d'une perspective dans laquelle l'orientation du maniement clinique ne se soumet pas à des rigueurs classificatoires préétablies, mais, effectivement, elle passe par la question du sujet dans sa relation à l'Autre, sa position dans le discours.

Mots clés: Diagnostic, psychanalyse, structure, position dans le discours 


\section{ARTIGOS}

(Diagnóstico en psicoanálisis: de la estructura al discurso)

El presente artículo propone una investigación sobre la cuestión del diagnóstico diferencial en el contexto de la práctica de orientación psicoanalítica. Se trata de una investigación trazada frente a una constatación clínica que se refiere a la operatividad del diagnóstico estructural, una observación de una perspectiva en la cual la orientación del manejo clínico no está impregnada por el rigor clasificatorio preestablecido, sino por la cuestión del sujeto en su relación con el Otro, su posición de discurso.

Palabras clave: Diagnóstico, psicoanálisis, estructura, posición de discurso

(Diagnose in der Psychoanalyse: Von der Struktur zum Diskurs)

Dieser Artikel beschreibt eine Forschungsarbeit zum Thema der Differentialdiagnose im Kontext der Praxis der psychoanalytischen Beratung. Es handelt sich um eine auf einer klinischen Bewertung beruhende Forschungsarbeit, welche die Durchführbarkeit der strukturellen Diagnose untersucht, ein Hinweis auf eine Perspektive, in der die klinische Praxis nicht auf eine vorgegebene klassifikatorische Strenge, sondern faktisch auf die Frage nach dem Subjekt in seiner Beziehung zum Anderen, seiner Position im Diskurs, beruht.

Schlüsselwörter: Diagnose, Psychoanalyse, Struktur, Position im Diskurs

Citação/Citation: Moreira, I. G., \& Teixeira, A. M. R. (2018, dezembro). Diagnóstico em psicanálise: da estrutura ao discurso. Revista Latinoamericana de Psicopatologia Fundamental, 21(4), 739-760. http://dx.doi.org/10.1590/1415-4714.2018v21n4p739.4.

Editores do artigo/Editors: Profa. Dra. Ana G. R. Oda e Profa. Dra. Sonia Leite.

Recebido/Received: 15.6.2018/ 6.15.2018 Aceito/Accepted: 18.8.2018 / 8.18.2018

Copyright: (C) 2009 Associação Universitária de Pesquisa em Psicopatologia Fundamental/ University Association for Research in Fundamental Psychopathology. Este é um artigo de livre acesso, que permite uso irrestrito, distribuição e reprodução em qualquer meio, desde que o autor e a fonte sejam citados / This is an open-access article, which permits unrestricted use, distribution, and reproduction in any medium, provided the original authors and sources are credited. 
Financiamento/Funding: Este trabalho recebeu apoio do Conselho Nacional de Desenvolvimento Científico e Tecnológico - CNPq (Brasília, DF, Br)/ This work was supported by the Conselho Nacional de Desenvolvimento Científico e Tecnológico - CNPq (Brasília, DF, Br).

Conflito de interesses/Conflict of interest: Os autores declaram que não há conflito de interesses / The authors have no conflict of interest to declare.

\section{Isa GontiJo Moreira}

Psicóloga pela Universidade Federal de Minas Gerais - UFMG (Belo Horizonte, MG, Br); Mestre em Psicologia com ênfase em Estudos Psicanalíticos pela Universidade Federal de Minas Gerais - UFMG (Belo Horizonte, MG, Br).

Rua Rio Grande do Norte, 726/505 - Funcionários

30130-131 Belo Horizonte, MG, Br.

760 gontijo.isa@hotmail.com

\section{Antônio M. R. Teixeira}

Psiquiatra; Psicanalista; Professor associado da Universidade Federal de Minas Gerais - UFMG (Belo Horizonte, MG, Br); Mestre em Filosofia Contemporânea pela FAFICHUFMG (Belo Horizonte,MG, Br); Doutor em Psicanálise pela Université Paris VIII (Paris, França). Membro da Escola Brasileira de Psicanálise.

Universidade Federal de Minas Gerais, Faculdade de Filosofia e Ciências Humanas, Departamento de Psicologia

Av. Antônio Carlos, 6627 - Pampulha

31270-901 Belo Horizonte, MG, Br.

amrteixeira@uol.com.br

This is an open-access article, which permits unrestricted use, distribution, the original authors and sources are credited. 